\title{
Relationship between Serum 25-Hydroxyvitamin D and Lower Extremity Arterial Disease in Type 2 Diabetes Mellitus Patients and the Analysis of the Intervention of Vitamin D
}

\author{
Wan Zhou and Shan-Dong Ye \\ Department of Endocrinology, Anhui Provincial Hospital Affiliated to Anhui Medical University, Hefei, Anhui 230001, China \\ Correspondence should be addressed to Shan-Dong Ye; zwdoccn@163.com
}

Received 17 January 2015; Revised 6 March 2015; Accepted 11 March 2015

Academic Editor: Ronald G. Tilton

Copyright (C) 2015 W. Zhou and S.-D. Ye. This is an open access article distributed under the Creative Commons Attribution License, which permits unrestricted use, distribution, and reproduction in any medium, provided the original work is properly cited.

\begin{abstract}
The aim of this study was to explore the relationship between serum 25-hydroxyvitamin D [25(OH)D] concentrations and lower extremity arterial disease (LEAD) in type 2 diabetes mellitus (T2DM) patients and to investigate the intervention effect of vitamin D. 145 subjects were assigned to a control group (Group NC), T2DM group (Group DM1), and T2DM complicated with LEAD group (Group DM2); then Group DM2 were randomly divided into Group DM3 who received oral hypoglycemic agents and Group DM4 who received oral hypoglycemic drugs and vitamin D3 therapy. Compared to Group NC, 25(OH)D was significantly lower in Group DM2 and marginally lower in Group DM1. In contrast to baseline and Group DM3, 25(OH)D rose while low density lipoprotein (LDL), retinol binding protein 4 (RBP4), and HbAlc significantly lowered in Group DM4. Statistical analysis revealed that 25(OH)D had a negative correlation with RBP4, duration, HbAlc, homeostasis model assessment for insulin resistance (HOMA-IR), and fasting plasma glucose (FPG). LDL, systolic blood pressure (SBP), FPG, and smoking were risk factors of LEAD while high density lipoprotein (HDL) and 25(OH)D were protective ones. Therefore, we deduced that low level of 25(OH)D is significantly associated with the occurrence of T2DM complicated with LEAD.
\end{abstract}

\section{Introduction}

Lower extremity arterial disease (LEAD) is a common peripheral arterial disease, which seriously affects the patient's functional capacity and quality of life [1]. It is one of the factors that contribute to the progressive and the critical courses of foot ulceration and amputation in type 2 diabetes mellitus (T2DM) patients [2], and it is frequently associated with coronary, cerebral, and renal artery diseases [3]. Vitamin D is a secosteroid, which is obtained from exposure to sunlight and through dietary sources including food and supplements. It is hydroxylated in the liver to 25hydroxyvitamin $\mathrm{D}[25(\mathrm{OH}) \mathrm{D}]$ and further hydroxylated in the kidney to form 1,25 -dihydroxyvatamin $\mathrm{D}[1,25(\mathrm{OH}) 2 \mathrm{D}$, calcitriol]. Although $1,25(\mathrm{OH}) 2 \mathrm{D}$ is considered to be the active form of vitamin $\mathrm{D}$, its level in the serum does not correlate with overall vitamin D status, whereas the $25(\mathrm{OH}) \mathrm{D}$ level is a more clinically relevant marker [4]. In addition to the traditional involvement of vitamin D in bone metabolism, several lines of evidence suggest a role for vitamin D in glucose levels, insulin resistance (IR), and prevalence of T2DM [5-8], and there are more and more studies that have found that it participated in systemic inflammation, immune, and lipid metabolism to reduce the risk of cardiovascular diseases [9], but few investigations suggest the association between vitamin $\mathrm{D}$ and T2DM complicated with LEAD. Hence, demonstrating a relationship between $25(\mathrm{OH}) \mathrm{D}$ and T2DM complicated with LEAD is necessary. Retinol binding protein 4 (RBP4) is a new adipokine identified by Yang et al. [10] using gene chip technology, which involves the occurrence of IR, T2DM, and macrovascular complications. Several researches [11] have shown that vitamin D is correlated with adiponectin, leptin, and other adipokines, but there are few studies analyzing a relationship between $25(\mathrm{OH}) \mathrm{D}$ and RBP4 in T2DM patients complicated with LEAD. Therefore, we realize the importance of further investigation in this area. In this effort, we conducted a clinic-based case-control study to explore the relationship among $25(\mathrm{OH}) \mathrm{D}, \mathrm{RBP} 4$, and T2DM 
complicated with LEAD and analyze the intervention effect of vitamin $\mathrm{D}$ for LEAD.

\section{Materials and Methods}

2.1. Subjects. 107 patients ( 63 males and 44 females) who were recruited from outpatient department were in line with the T2DM diagnosis standard delivered by World Health Organization (WHO) in October 1999. They were hospitalized from October 2012 to January 2013 in the Department of Endocrinology in Anhui Provincial Hospital. This study was conducted in accordance with the tenets of the World Medical Association's Declaration of Helsinki and had been approved by the China Ethics Committee. Written informed consent was obtained from all participants.

The subjects who met the following criteria were excluded: (1) individuals who had acute complications of T2DM, retinopathy, nephropathy, and other chronic complications, cancer, vitamin A deficiency, liver and kidney dysfunction, osteoporosis, and other history of bone metabolic disorders; (2) those taking drugs including vitamins, calcium, lipid lowering drugs, estrogen, and other drugs affecting bone metabolism. All the patients were assigned into 2 groups: the one that is without complications (Group DM1: 25 males, 20 females) and the other that is complicated with LEAD (Group DM2: 38 males, 24 females); then subjects in Group DM2 were further divided into Group DM3 (16 males, 15 females) and Group DM4 (22 males, 9 females). Patients in these 2 groups were both treated with hypoglycemic drugs, and additionally patients of Group DM4 were orally administered vitamin D3 1000 IU daily. In this period 2 subjects in Group DM3 were out of touch and 4 subjects in Group DM4 could not insist on the intervention therapy and quitted. The relevant characteristics were tested and $\mathrm{ABI}$ was reexamined in Groups DM3 and DM4 after 12 weeks of therapy. 38 age-sex-matched healthy people with no hypertension or impaired glucose tolerance were chosen at the same period as a control group (Group NC) (20 males and 18 females).

2.2. ABI Measurement. The Doppler instrument (Bidop ES$100-\mathrm{v} 3$ produced in Japan) was adapted. All the ABI measurements were performed with the subjects in the supine position, a blood pressure cuff was placed on patients' upper arms, and it was inflated until no brachial pulse was detected by the Doppler device. The cuff was then slowly deflated until the Doppler-detected pulse returned to measure brachial systolic blood pressure (BSBP). This maneuver was repeated on the leg, with the cuff being wrapped around the distal calf and the Doppler device being placed over the dorsalis pedis or the posterior tibial artery to measure ankle systolic blood pressure (ASBP) [12]. Ankle brachial index $(\mathrm{ABI})=$ $\mathrm{ASBP} / \mathrm{BSBP}$ and $\mathrm{ABI}<0.9$ indicated the presence of LEAD [13].

2.3. Assays. All the subjects took balanced diets for 3 days and then fasted overnight for 12 hours. Clinical characteristics including sex, age, diabetes duration, height, weight, hip circumference, blood pressure, and history of smoking were collected. Body mass index (BMI) and waist-hip ratio
(WHR) were calculated as weight divided by height squared $\left(\mathrm{kg} / \mathrm{m}^{2}\right)$ and waist circumference divided by hip circumference, respectively. Systolic blood pressure (SBP) and diastolic blood pressure (DBP) were measured using a digital automatic blood pressure monitor. Patients' blood samples were kept frozen at $-80^{\circ} \mathrm{C}$ until analysis. Fasting plasma glucose (FPG), total cholesterol (TC), triglycerides (TG), low density lipoprotein (LDL), and high density lipoprotein (HDL) were detected by Hitachi 76002020 automatic biochemical analyzer. $\mathrm{HbAlC}$ was conducted by high-pressure liquid chromatography (Bio-Rad variant turbo II analyzer). Fasting insulin (FINS) was tested by radioimmunoassay (Linco Research, St. Charles, USA). The homeostasis model assessment for insulin resistance (HOMA-IR) was calculated according to the formula HOMA-IR = FINS $(\mathrm{mU} / \mathrm{L}) \times$ FPG $(\mathrm{mmol} / \mathrm{L}) / 22.5$. Serum $25(\mathrm{OH}) \mathrm{D}$ concentrations were detected via radioimmunoassay (Diasorin Stillwater, MN, USA). Sufficiency was indicated when $25(\mathrm{OH}) \mathrm{D} \geq 30 \mathrm{ng} / \mathrm{mL}$, insufficiency when $20 \mathrm{ng} / \mathrm{mL} \leq 25(\mathrm{OH}) \mathrm{D}<30 \mathrm{ng} / \mathrm{mL}$, and deficiency when $25(\mathrm{OH}) \mathrm{D}<20 \mathrm{ng} / \mathrm{mL}$ [14]. The level of RBP4 was measured by enzyme-linked immunoassay (AssayPro, MO, USA).

2.4. Statistical Method. All data were calculated by SPSS17.0 statistical software (SPSS Inc., Chicago, IL, USA). Continuous variables are presented as mean \pm standard deviation $(\bar{x} \pm s)$, or median and interquartile range (25th and 75th percentile) in cases of skewed distributions, while categorical variables are presented as percentages. These groups were compared using two-sample $t$-test, Mann Whitney $U$ test, or chisquare test. Paired sample $t$-test was used to compare the differences before and after treatment. Pearson's correlation coefficient or Spearman's rank correlation coefficient was used to assess the relationship between $25(\mathrm{OH}) \mathrm{D}$ and other markers. Multivariable logistic regression analysis was used to calculate the ORs and $95 \%$ confidence intervals for LEAD; statistical significance was accepted at $P<0.05$.

\section{Results}

3.1. Clinical and Biochemical Characteristics. The indexes of the subjects were listed in Table 1 . There were no differences of sex between the 3 groups $(P>0.05)$. Participants in Group DM2 had a longer duration than in Group DM1; the differences were statistically significant $(P<0.05)$. Serum $25(\mathrm{OH}) \mathrm{D}$ concentrations were $24.77 \pm 5.9 \mathrm{ng} / \mathrm{mL}, 17.32 \pm$ $7.42 \mathrm{ng} / \mathrm{mL}$, and $12.63 \pm 7.83 \mathrm{ng} / \mathrm{mL}$ in Groups NC, DM1, and DM2, respectively; compared with Group NC, 25(OH)D decreased in Groups DM1 and DM2 and the decrease in Group DM2 was more significant $(P<0.05)$. RBP4 level was lower in T2DM patients with LEAD compared to the patients without LEAD and healthy people $(P<0.05)$. Raised FPG, FINS, HbA1C, TC, TG, LDL, HOMA-IR, SBP, and WHR and decreased HDL in Groups DM1 and DM2 were exhibited as compared with Group NC $(P<0.05)$; age, FPG, LDL, SBP, HbAlC, and the rate of smoking increased and HDL decreased in Group DM2 compared with the other 2 groups $(P<0.05)$. 
TABLE 1: The comparison of basic characteristics in Groups NC, DM1, and DM2.

\begin{tabular}{lccc}
\hline & NC $(n=38)$ & DM1 $(n=45)$ & DM2 $(n=62)$ \\
\hline Age (y) & $56.61 \pm 7.45$ & $56.24 \pm 4.23$ & $58.85 \pm 6.18^{\mathrm{b}, \mathrm{d}}$ \\
Duration (y) & - & $6.45 \pm 2.84$ & $9.31 \pm 4.27^{\mathrm{d}}$ \\
FPG (mmol/L) & $4.65 \pm 0.45$ & $7.98 \pm 1.26^{\mathrm{b}}$ & $8.60 \pm 1.24^{\mathrm{b}, \mathrm{c}}$ \\
FINS (mU/L) & $7.33 \pm 1.28$ & $8.98 \pm 3.76^{\mathrm{b}}$ & $9.22 \pm 2.55^{\mathrm{b}}$ \\
TC (mmol/L) & $4.78 \pm 0.43$ & $5.08 \pm 0.59^{\mathrm{a}}$ & $5.12 \pm 0.43^{\mathrm{b}}$ \\
TG (mmol/L) & $1.52 \pm 0.42$ & $2.52 \pm 0.32^{\mathrm{b}}$ & $2.47 \pm 0.37^{\mathrm{b}}$ \\
LDL (mmol/L) & $2.33 \pm 0.45$ & $2.63 \pm 0.69^{\mathrm{a}}$ & $3.10 \pm 0.74^{\mathrm{b}, \mathrm{d}}$ \\
HDL (mmol/L) & $1.42 \pm 0.28$ & $1.26 \pm 0.26^{\mathrm{a}}$ & $1.11 \pm 0.12^{\mathrm{b}, \mathrm{d}}$ \\
HOMA-IR & $1.52 \pm 0.32$ & $3.13 \pm 1.28^{\mathrm{b}}$ & $3.52 \pm 1.02^{\mathrm{b}}$ \\
25(OH)D (ng/mL) & $24.77 \pm 5.92$ & $17.32 \pm 7.42^{\mathrm{b}}$ & $12.63 \pm 7.83^{\mathrm{b}, \mathrm{d}}$ \\
RBP4 $(\mu \mathrm{g} / \mathrm{mL})$ & $14.82 \pm 1.84$ & $29.28 \pm 2.23^{\mathrm{b}}$ & $39.00 \pm 2.10^{\mathrm{b}, \mathrm{d}}$ \\
SBP (mmHg) & $120(120,130)$ & $134(127,145)^{\mathrm{b}}$ & $153(144,159)^{\mathrm{b}, \mathrm{d}}$ \\
BMI (kg/m $\left.{ }^{2}\right)$ & $23.50 \pm 2.07$ & $25.61 \pm 2.61^{\mathrm{b}}$ & $24.73 \pm 3.56$ \\
HbAlc $(\%)$ & $5.96 \pm 0.65$ & $7.95 \pm 1.21^{\mathrm{b}}$ & $7.38 \pm 0.72^{\mathrm{b}, \mathrm{c}}$ \\
WHR & $0.76 \pm 0.03$ & $0.89 \pm 0.03^{\mathrm{b}}$ & $0.87 \pm 0.04^{\mathrm{b}}$ \\
Smoking $(\%)$ & $9(23.7 \%)$ & $11(24.4 \%)$ & $40(64.5 \%)^{\mathrm{b}, \mathrm{d}}$ \\
Male $(\%)$ & $20(52.6 \%)$ & $25(55.6 \%)$ & $38(61.3 \%)$ \\
\hline
\end{tabular}

Note: compared with Group NC, ${ }^{\mathrm{a}} P<0.05,{ }^{\mathrm{b}} P<0.01$; compared with Group DM1, ${ }^{\mathrm{c}} P<0.05,{ }^{\mathrm{d}} P<0.01$.

TABle 2: Cases with different levels of 25(OH)D in Groups NC, DM1, and DM2.

\begin{tabular}{lcccr}
\hline Group & $25(\mathrm{OH}) \mathrm{D}<20$ & $\leq 20<25(\mathrm{OH}) \mathrm{D} \leq 30$ & $25(\mathrm{OH}) \mathrm{D}>30$ & Chi-squared \\
\hline NC & $6(15.8 \%)$ & $25(65.8 \%)$ & $7(18.4 \%)$ & 38.84 \\
DM1 & $29(64.4 \%)$ & $12(26.7 \%)$ & $4(8.9 \%)$ & $<0.01$ \\
DM2 & $48(77.4 \%)$ & $9(14.5 \%)$ & $5(8.1 \%)$ & \\
\hline
\end{tabular}

Note: NC versus DM1: $P<0.01 ;$ NC versus DM2: $P<0.01 ;$ DM1 versus DM2: $P>0.05$.

3.2. Cases with Different Levels of 25(OH)D among Three Groups. As depicted in Table 2, approximately $18.4 \%$ of subjects were classified as $25(\mathrm{OH}) \mathrm{D}$ sufficient and $65.8 \%$ were classified as $25(\mathrm{OH}) \mathrm{D}$ insufficient; only $15.8 \%$ of subjects were classified as 25(OH)D deficient in Group NC. In Group DM1, only $8.9 \%$ of subjects had normal $25(\mathrm{OH}) \mathrm{D}$ level and $26.7 \%$ had insufficiency $25(\mathrm{OH}) \mathrm{D}$ level while $64.4 \%$ were $25(\mathrm{OH}) \mathrm{D}$ deficient. The percentages of $25(\mathrm{OH}) \mathrm{D}$ deficiency, insufficiency, and sufficiency were $77.4 \%, 14.5 \%$, and $8.1 \%$, respectively, in Group DM2. The percentages of sufficient 25(OH)D level in Groups DM1 and DM2 were both lower than the percentage in Group NC, and the difference was statistically significant $(P<0.05)$.

3.3. The Levels of Clinical Characteristics before and after the Treatment in Diabetic Groups Complicated with LEAD. There was no significant difference between Groups DM3 and DM4 at baseline. After 12 weeks of vitamin D supplementation in Group DM4, 25(OH)D level increased and LDL, RBP4, and $\mathrm{HbA1C}$ decreased significantly when compared with baseline $(P<0.05)$, while, following 12 -week basic therapy of hypoglycemic drugs in Group DM3, only RBP4 and HbA1C decreased $(P<0.05)$. Supplementation with vitamin $\mathrm{D}$ for 12 weeks in diabetics with LEAD significantly raised $25(\mathrm{OH}) \mathrm{D}$ level and lowered LDL, RBP4, and HbAlc relative to baseline and unsupplemented diabetics $(P<0.05)$. Reexamination of ABI by Doppler ultrasonography for subjects in Group
DM3 and Group DM4 after 12 weeks showed that there were, respectively, 5 cases in Group DM3 and 10 cases in Group DM4 whose values increased to $\geq 0.9$, and the difference was not statistically significant $(P>0.05)$ (Table 3$)$.

3.4. Correlations between 25(OH)D and Other Indexes. As depicted in Table 4 the correlation analysis results suggested that the level of $25(\mathrm{OH}) \mathrm{D}$ was inversely associated with duration $(r=-0.663, P<0.05)$, HbAlc $(r=-0.482$, $P<0.05)$, RBP4 $(r=-0.538, P<0.05)$, FPG $(r=-0.229)$, and HOMA-IR $(r=-0.267, P<0.05)$, while there was no significant correlation between $25(\mathrm{OH}) \mathrm{D}$ and the remaining indicators $(P>0.05)$. 25(OH)D had a positive correlation trend with HDL, but the difference was not statistically significant $(P>0.05)$.

3.5. Independent Factors for the Presence of LEAD. As shown in Table 5, the presence of LEAD in T2DM patients was used as the dependent variable, while $25(\mathrm{OH}) \mathrm{D}, \mathrm{TC}, \mathrm{TG}, \mathrm{HDL}$, LDL, BMI, RBP4, HOMA-IR, SBP, FINS, FPG, WHR, age, sex, duration, and smoking were used as the independent variables. Multivariable logistic regression analysis showed that smoking $(\mathrm{OR}=5.565,95 \% \mathrm{CI}=1.379-22.458), \mathrm{FPG}$ $(\mathrm{OR}=1.818,95 \% \mathrm{CI}=1.027-3.217), \mathrm{SBP}(\mathrm{OR}=1.167,95 \%$ $\mathrm{CI}=1.081-1.260)$, and $\mathrm{LDL}(\mathrm{OR}=2.746,95 \% \mathrm{CI}=1.122-$ 6.721) were significant negative predictors. $\mathrm{HDL}(\mathrm{OR}=2.746$, 
TABLE 3: The comparison of characteristics before and after treatment in Groups DM3 and DM4.

\begin{tabular}{|c|c|c|c|c|c|c|}
\hline \multirow{2}{*}{ Variable } & \multicolumn{3}{|c|}{ Group DM4 $(n=27)$} & \multicolumn{3}{|c|}{ Group DM3 $(n=29)$} \\
\hline & $0 \mathrm{w}$ & $12 \mathrm{w}$ & $D$-value & $0 \mathrm{w}$ & $12 \mathrm{w}$ & $D$-value \\
\hline TC (mmol/L) & $5.12 \pm 0.43$ & $5.25 \pm 0.32$ & $-0.13 \pm 0.47$ & $5.17 \pm 0.41$ & $5.3 \pm 0.38$ & $-0.13 \pm 0.5$ \\
\hline TG (mmol/L) & $2.47 \pm 0.35$ & $2.33 \pm 0.19^{\mathrm{b}}$ & $-0.14 \pm 0.38$ & $2.47 \pm 0.40$ & $2.50 \pm 0.32$ & $-0.03 \pm 0.52$ \\
\hline $\mathrm{LDL}(\mathrm{mmol} / \mathrm{L})$ & $3.18 \pm 0.72$ & $2.43 \pm 0.41^{\mathrm{a}, \mathrm{b}}$ & $-0.72 \pm 0.85$ & $2.91 \pm 0.73$ & $3.03 \pm 0.60$ & $-0.12 \pm 1.00$ \\
\hline $\mathrm{HDL}(\mathrm{mmol} / \mathrm{L})$ & $1.12 \pm 0.11$ & $1.09 \pm 0.26$ & $-0.03 \pm 0.27$ & $1.11 \pm 0.12$ & $1.19 \pm 0.21$ & $-0.08 \pm 0.25$ \\
\hline $25(\mathrm{OH}) \mathrm{D}(\mathrm{ng} / \mathrm{mL})$ & $12.39 \pm 8.37$ & $19.27 \pm 2.33^{\mathrm{a}, \mathrm{b}}$ & $-6.89 \pm 9.03^{b}$ & $13.30 \pm 7.76$ & $11.66 \pm 2.37$ & $1.63 \pm 7.63$ \\
\hline $\mathrm{RBP} 4(\mu \mathrm{g} / \mathrm{mL})$ & $39.09 \pm 2.32$ & $25.33 \pm 1.68^{\mathrm{a}, \mathrm{b}}$ & $13.76 \pm 3.20^{\mathrm{b}}$ & $39.02 \pm 1.97$ & $35.44 \pm 2.17^{\mathrm{a}}$ & $3.58 \pm 3.05$ \\
\hline BMI $\left(\mathrm{kg} / \mathrm{m}^{2}\right)$ & $25.05 \pm 3.30$ & $23.95 \pm 2.81$ & $1.10 \pm 4.11$ & $24.09 \pm 3.77$ & $23.71 \pm 2.85$ & $0.38 \pm 4.65$ \\
\hline HbAlc (\%) & $7.38 \pm 0.65$ & $5.95 \pm 0.48^{\mathrm{a}, \mathrm{b}}$ & $1.43 \pm 0.87^{\mathrm{b}}$ & $7.35 \pm 0.78$ & $6.74 \pm 0.59^{\mathrm{a}}$ & $0.61 \pm 0.92$ \\
\hline WHR & $0.87 \pm 0.04$ & $0.87 \pm 0.04$ & $0.00 \pm 0.05$ & $0.87 \pm 0.04$ & $0.86 \pm 0.03$ & $0.01 \pm 0.05$ \\
\hline
\end{tabular}

Note: comparison within the group, ${ }^{\mathrm{a}} \mathrm{P}<0.05$; comparison between two groups, ${ }^{\mathrm{b}} \mathrm{P}<0.05$.

TABLE 4: The analysis of the correlation between $25(\mathrm{OH}) \mathrm{D}$ and the indicators of patients in Group T2DM.

\begin{tabular}{lccc}
\hline Variable & Number & $r$ & $P$ \\
\hline Age $(\mathrm{y})$ & 107 & -0.074 & 0.448 \\
Duration $(\mathrm{y})$ & 107 & -0.663 & $<0.001$ \\
FPG $(\mathrm{mmol} / \mathrm{L})$ & 107 & -0.229 & 0.018 \\
FINS $(\mathrm{mmol} / \mathrm{L})$ & 107 & -0.175 & 0.072 \\
TC $(\mathrm{mmol} / \mathrm{L})$ & 107 & -0.009 & 0.927 \\
TG $(\mathrm{mmol} / \mathrm{L})$ & 107 & -0.082 & 0.403 \\
LDL $(\mathrm{mmol} / \mathrm{L})$ & 107 & -0.113 & 0.247 \\
HDL $(\mathrm{mmol} / \mathrm{L})$ & 107 & 0.113 & 0.247 \\
HOMA-IR & 107 & -0.267 & 0.006 \\
RBP4 $(\mu \mathrm{g} / \mathrm{mL})$ & 107 & -0.538 & $<0.001$ \\
SBP $(\mathrm{mmHg})$ & 107 & -0.104 & 0.287 \\
BMI $\left(\mathrm{kg} / \mathrm{m}^{2}\right)$ & 107 & -0.066 & 0.497 \\
HbAlc $(\%)$ & 107 & -0.482 & $<0.001$ \\
WHR & 107 & -0.181 & 0.063 \\
\hline
\end{tabular}

$95 \% \mathrm{CI}=0-0.432)$ and $25(\mathrm{OH}) \mathrm{D}(\mathrm{OR}=0.892,95 \% \mathrm{CI}=$ $0.813-0.978)$ were positive predictors. The equation is as follows:

$$
\begin{aligned}
y= & \operatorname{logit}(p) \\
= & 0.598 * \mathrm{FPG}+1.01 * \mathrm{LDL} \\
& -4.25 * \mathrm{HDL}-0.114 * 25(\mathrm{OH}) \mathrm{D} \\
& +0.155 * \mathrm{SBP}+1.717 * \text { smoking }-23.661 .
\end{aligned}
$$

\section{Discussion}

RBP4 is a molecule found in the circulation, thought to be secreted mainly by adipose tissue and the liver. Increased serum RBP4 levels have been reported in subjects with obesity, IR, and T2DM and in other insulin-resistant states, such as metabolic syndrome and vascular complications of DM [15]. Cabré et al. [16] pointed out that RBP4 would increase in patients of T2DM complicated with coronary heart disease, and when the level of RBP 4 increased by $1 / 4$, the risk of cardiovascular disease would increase by 2.5 times. In this study, the level of RBP4 was higher in patients of T2DM with LEAD than in patients of T2DM and healthy people. Therefore, RBP4 is involved in the pathogenesis of T2DM with LEAD. Metheniti et al. [17] reported that $25(\mathrm{OH}) \mathrm{D}$ was low in ultra obese young females and it was significantly associated with RBP4 and neutrophil gelatinase-associated lipocalin (NGAL). We found that there was a negative correlation between $25(\mathrm{OH}) \mathrm{D}$ and RBP4; the concentrations of RBP4 decreased after vitamin D supplementation in the study. Vitamin D may reduce peripheral IR by inhibiting the expression of peroxisome proliferator-activated receptor$\gamma(\mathrm{PPAR}-\gamma)$ and the differentiation from preadipocytes to mature adipocytes [18]. This result suggests that one of the reasons for IR led by vitamin D deficiency in T2DM patients is the regulation of RBP4.

The third national health and nutrition examination survey (NHANES-III) found that, compared with residents with normal concentrations of $25(\mathrm{OH}) \mathrm{D}$, residents with low concentrations of 25(OH)D had a higher incidence of peripheral arterial disease [19]. In this study, the level of $25(\mathrm{OH}) \mathrm{D}$ in T2DM group was lower than the one in control group, and it was the lowest in T2DM with LEAD group; $25(\mathrm{OH}) \mathrm{D}$ was a factor to protect DM patients from the pathogenesis of LEAD. Our findings were consistent with the research of FahrleitnerPammer et al. [20] about the relationship between 25(OH)D and T2DM with LEAD. The possible mechanisms of the involvement for 25(OH)D include the following. (1) Vitamin $\mathrm{D}$ can promote pancreatic $\beta$ cells to secrete insulin by adjusting vitamin $\mathrm{D}$ receptor (VDR) and vitamin-D-dependent calcium-binding protein (DBP) in pancreatic tissue. It can also reduce IR in peripheral tissues by regulating inflammatory cytokines and inhibiting the expression of PPAR- $\gamma$ [18]. Besides, it can affect insulin sensitivity by stimulating $(\operatorname{PPAR} \delta)$ and the gene expression of insulin receptor [21]. (2) Calcitriol can regulate rennin angiotensin-aldosterone system (RAAS), inhibit the expression of renin, and adjust the synthesis and secretion of atrial natriuretic peptide. (3) Vitamin D can upregulate the expression of related protein of delaying arterial calcification including vascular endothelial growth factor and matrix metalloproteinase-9. (4) Vitamin D can reduce the occurrence of arterial calcification and atherosclerosis by inhibiting angiogenesis, smoothing muscle cells proliferation, and playing a role in immune 
TABLE 5: Multivariable logistic regression analysis for the predictors of LEAD.

\begin{tabular}{|c|c|c|c|c|c|c|c|}
\hline \multirow{2}{*}{ Variable } & \multirow{2}{*}{$B$} & \multirow{2}{*}{ S.E. } & \multirow{2}{*}{ Wals } & \multirow{2}{*}{ Sig. } & \multirow{2}{*}{ OR } & \multicolumn{2}{|c|}{$95 \% \mathrm{CI}$} \\
\hline & & & & & & Lower & Upper \\
\hline FPG (mmol/L) & 0.598 & 0.291 & 4.215 & 0.040 & 1.818 & 1.027 & 3.217 \\
\hline $\mathrm{LDL}(\mathrm{mmol} / \mathrm{L})$ & 1.010 & 0.457 & 4.893 & 0.027 & 2.746 & 1.122 & 6.721 \\
\hline $\mathrm{HDL}(\mathrm{mmol} / \mathrm{L})$ & -4.250 & 1.741 & 5.962 & 0.015 & 0.014 & 0.000 & 0.432 \\
\hline $25(\mathrm{OH}) \mathrm{D}(\mathrm{ng} / \mathrm{mL})$ & -0.114 & 0.047 & 5.933 & 0.015 & 0.892 & 0.813 & 0.978 \\
\hline SBP (mmHg) & 0.155 & 0.039 & 15.731 & 0.000 & 1.167 & 1.081 & 1.260 \\
\hline Smoking & 1.717 & 0.712 & 5.815 & 0.016 & 5.565 & 1.379 & 22.458 \\
\hline Quantity & -23.661 & 6.934 & 11.643 & 0.001 & 0.000 & & \\
\hline
\end{tabular}

regulation with VDR mediation of immune cells. (5) A lack of calcitriol results in an increase in the serum parathyroid hormone (PTH) levels. Excess PTH levels may at least in part promote cardiovascular disease by increasing the cardiac contractility and myocardial calcification [22]. (6) Vitamin $\mathrm{D}$ can improve the inflammation state $[23,24]$ and reduce chronic inflammatory reaction of the arterial wall [25] by inhibiting the secretion of inflammatory cytokines, such as IL-6, TNF- $\alpha$, and C-reactive protein (CRP) [26]. (7) Calcitriol can inhibit foam cells formation in vascular wall by reducing acetylation and reduce the level of oxidized LDL in T2DM patients.

A 20-year retrospective study has found that [27] the incidence of DM complicated with cardiovascular diseases reduced by $33 \%$ in population with $800 \mathrm{IU}$ vitamin D and $1200 \mathrm{mg}$ calcium of daily intake compared to those with 400 IU vitamin D and $600 \mathrm{mg}$ calcium of daily intake, which suggests that vitamin $\mathrm{D}$ supplementation might become an effective measurement to prevent the occurrences of T2DM complicated with macrovascular diseases. Major et al. [28] suggested that oral supplementation of vitamin D could regulate blood lipid. In this study, the levels of LDL and RBP4 reduced in T2DM group after the intervention of vitamin $\mathrm{D}$, and, simultaneously, the incidence rate of LEAD in T2DM group also decreased after the intervention of vitamin $\mathrm{D}$. Therefore, vitamin D supplementation can protect T2DM patients from being complicated with LEAD ultimately by improving IR and lipid metabolism and inhibiting inflammation.

\section{Conclusion}

There were several limitations in our study. The sample size was relatively small and we did not consider the influence of outdoor activities and seasonal variation on the level of vitamin $\mathrm{D}$. However, the study was conducted in winter so that the impact of sun exposure was minimized. In conclusion, the phenomenon of vitamin $\mathrm{D}$ deficiency amongst T2DM patients was more and more prevalent, and, with the advantages of low price and validated long-term safety, the supplementation of vitamin $\mathrm{D}$ would be one of the intervening measurements for the presentation of T2DM and its vascular complications.

\section{Conflict of Interests}

All authors have no conflict of interests regarding this paper.

\section{Acknowledgment}

This work was supported by grants from the Project of Provincial Natural Science Research of University of Anhui Province of China (no. KJ2012Z178).

\section{References}

[1] A. J. Hills, J. Shalhoub, A. C. Shepherd, and A. H. Davies, "Peripheral arterial disease," British Journal of Hospital Medicine, vol. 70, no. 10, pp. 560-565, 2009.

[2] K. O. Thejaswini, M. S. Roopakala, G. Dayananda, S. P. Chandrakala, and K. M. P. Kumar, "A study of association of Ankle Brachial Index (ABI) and the highly sensitive $\mathrm{C}$-reactive protein (hsCRP) in Type 2 diabetic patients and in normal subjects," Journal of Clinical and Diagnostic Research, vol. 7, no. 1, pp. 46-50, 2013.

[3] Q. Chen, C. Y. Smith, K. R. Bailey, P. W. Wennberg, and I. J. Kullo, "Disease location is associated with survival in patients with peripheral arterial disease," Journal of the American Heart Association, vol. 2, no. 5, Article ID e000304, 2013.

[4] L. Mosekilde, "Vitamin D requirement and setting recommendation levels: long-term perspectives," Nutrition Reviews, vol. 66, no. 2, pp. S170-S177, 2008.

[5] M. F. Holick, N. C. Binkley, H. A. Bischoff-Ferrari et al., "Evaluation, treatment, and prevention of vitamin D deficiency: an Endocrine Society clinical practice guideline," Journal of Clinical Endocrinology \& Metabolism, vol. 96, no. 12, pp. 19111930, 2011.

[6] A. Hossein-nezhad, A. Spira, and M. F. Holick, "Influence of vitamin $\mathrm{D}$ status and vitamin $\mathrm{D}_{3}$ supplementation on genome wide expression of white blood cells: a randomized doubleblind clinical trial," PLoS ONE, vol. 8, no. 3, Article ID e58725, 2013.

[7] E. Liu, J. B. Meigs, A. G. Pittas et al., "Plasma 25-hydroxyvitamin $\mathrm{D}$ is associated with markers of the insulin resistant phenotype in nondiabetic adults," Journal of Nutrition, vol. 139, no. 2, pp. 329-334, 2009.

[8] S. Kayaniyil, R. Vieth, R. Retnakaran et al., "Association of vitamin $\mathrm{D}$ with insulin resistance and beta-cell dysfunction in subjects at risk for type 2 diabetes," Diabetes Care, vol. 33, no. 6, pp. 1379-1381, 2010.

[9] S. Makariou, E. N. Liberopoulos, M. Elisaf, and A. Challa, "Novel roles of vitamin D in disease: what is new in 2011?" European Journal of Internal Medicine, vol. 22, no. 4, pp. 355362, 2011.

[10] Q. Yang, T. E. Graham, N. Mody et al., "Serum retinol binding protein 4 contributes to insulin resistance in obesity and type 2 diabetes," Nature, vol. 436, no. 7049, pp. 356-362, 2005. 
[11] S. Kim, J. Lim, S. Kye, and H. Joung, "Association between vitamin D status and metabolic syndrome risk among Korean population: based on the Korean National Health and Nutrition Examination Survey IV-2, 2008," Diabetes Research and Clinical Practice, vol. 96, no. 2, pp. 230-236, 2012.

[12] I. Kojima, T. Ninomiya, J. Hata et al., "A low ankle brachial index is associated with an increased risk of cardiovascular disease: the hisayama study," Journal of Atherosclerosis and Thrombosis, vol. 21, no. 9, pp. 966-973, 2014.

[13] D. Sacks, C. W. Bakal, P. T. Beatty et al., "Position statement on the use of the ankle-brachial index in the evaluation of patients with peripheral vascular disease: a consensus statement developed by the standards division of the society of cardiovascular \& interventional radiology," Journal of Vascular and Interventional Radiology, vol. 13, no. 4, article 353, 2002.

[14] R. Jorde, M. Sneve, P. Torjesen, and Y. Figenschau, "No improvement in cardiovascular risk factors in overweight and obese subjects after supplementation with vitamin $\mathrm{D}_{3}$ for 1 year," Journal of Internal Medicine, vol. 267, no. 5, pp. 462-472, 2010.

[15] T. E. Graham, Q. Yang, M. Blüher et al., "Retinol-binding protein 4 and insulin resistance in lean, obese, and diabetic subjects," The New England Journal of Medicine, vol. 354, no. 24, pp. 2552-2563, 2006.

[16] A. Cabré, I. Lázaro, J. Girona et al., "Retinol-binding protein 4 as a plasma biomarker of renal dysfunction and cardiovascular disease in Type 2 diabetes," Journal of Internal Medicine, vol. 262, no. 4, pp. 496-503, 2007.

[17] D. Metheniti, S. Sakka, M. Dracopoulou et al., "Decreased circulating 25-(OH) Vitamin D concentrations in obese female children and adolescents: positive associations with Retinol Binding Protein-4 and Neutrophil Gelatinase-associated Lipocalin," Hormones (Athens), vol. 12, no. 3, pp. 397-404, 2013.

[18] M. F. McCarty and C. A. Thomas, "PTH excess may promote weight gain by impeding catecholamine-induced lipolysisimplications for the impact of calcium, vitamin D, and alcohol on body weight," Medical Hypotheses, vol. 61, no. 5-6, pp. 535542, 2003.

[19] M. L. Melamed, P. Muntner, E. D. Michos et al., "Serum 25-hydroxyvitamin D levels and the prevalence of peripheral arterial disease: results from NHANES 2001 to 2004," Arteriosclerosis, Thrombosis, and Vascular Biology, vol. 28, no. 6, pp. 1179-1185, 2008.

[20] A. Fahrleitner-Pammer, A. Obernosterer, E. Pilger et al., "Hypovitaminosis D, impaired bone turnover and low bone mass are common in patients with peripheral arterial disease," Osteoporosis International, vol. 16, no. 3, pp. 319-324, 2005.

[21] T. W. Dunlop, S. Väisänen, C. Frank, F. Molnár, L. Sinkkonen, and C. Carlberg, "The human peroxisome proliferator-activated receptor $\delta$ gene is a primary target of $1 \alpha, 25$-dihydroxyvitamin $\mathrm{D}_{3}$ and its nuclear receptor," Journal of Molecular Biology, vol. 349 , no. 2, pp. 248-260, 2005.

[22] O. J. de Boer, F. Hirsch, A. C. van der Wal, C. M. van der Loos, P. K. Das, and A. E. Becker, "Costimulatory molecules in human atherosclerotic plaques: an indication of antigen specific T lymphocyte activation," Atherosclerosis, vol. 133, no. 2, pp. 227-234, 1997.

[23] A. B. Awad, L. Alappat, and M. Valerio, "Vitamin D and metabolic syndrome risk factors: evidence and mechanisms," Critical Reviews in Food Science and Nutrition, vol. 52, no. 2, pp. 103-112, 2012.

[24] V. Lee, E. Rekhi, J. Hoh Kam, and G. Jeffery, "Vitamin D rejuvenates aging eyes by reducing inflammation, clearing amyloid beta and improving visual function," Neurobiology of Aging, vol. 33, no. 10, pp. 2382-2389, 2012.

[25] S. Rueda, C. Fernández-Fernández, F. Romero, M. J. Martínez de Osaba, and J. Vidal, "Vitamin D, PTH, and the metabolic syndrome in severely obese subjects," Obesity Surgery, vol. 18, no. 2, pp. 151-154, 2008.

[26] A. Bellia, C. Garcovich, M. D’Adamo et al., "Serum 25hydroxyvitamin D levels are inversely associated with systemic inflammation in severe obese subjects," Internal and Emergency Medicine, vol. 8, no. 1, pp. 33-40, 2013.

[27] A. G. Pittas, B. Dawson-Hughes, T. Li et al., "Vitamin D and calcium intake in relation to type 2 diabetes in women," Diabetes Care, vol. 29, no. 3, pp. 650-656, 2006.

[28] G. C. Major, F. Alarie, J. Doré, S. Phouttama, and A. Tremblay, "Supplementation with calcium + vitamin D enhances the beneficial effect of weight loss on plasma lipid and lipoprotein concentrations," American Journal of Clinical Nutrition, vol. 85, no. 1, pp. 54-59, 2007. 


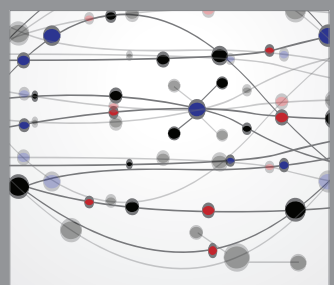

The Scientific World Journal
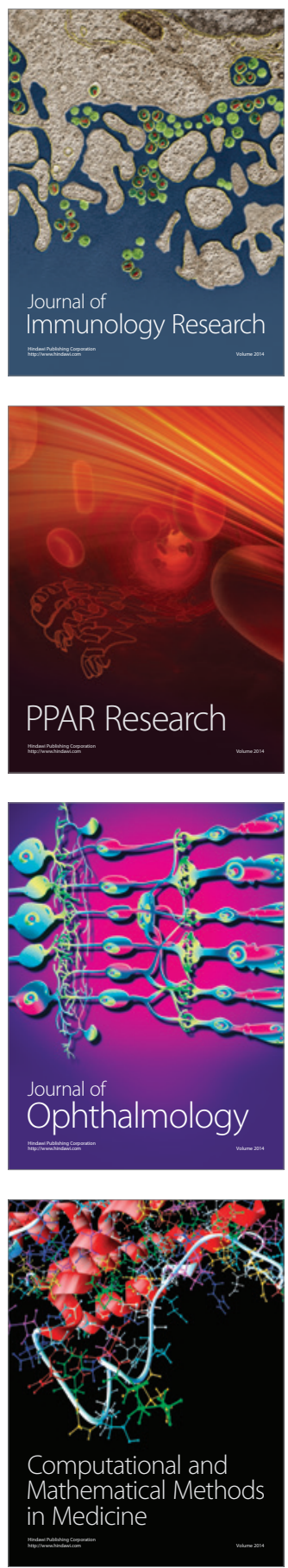

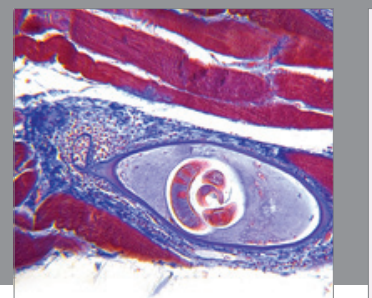

Gastroenterology

Research and Practice
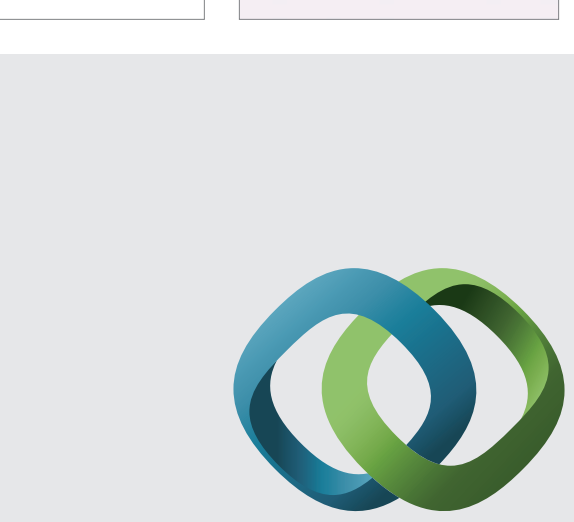

\section{Hindawi}

Submit your manuscripts at

http://www.hindawi.com
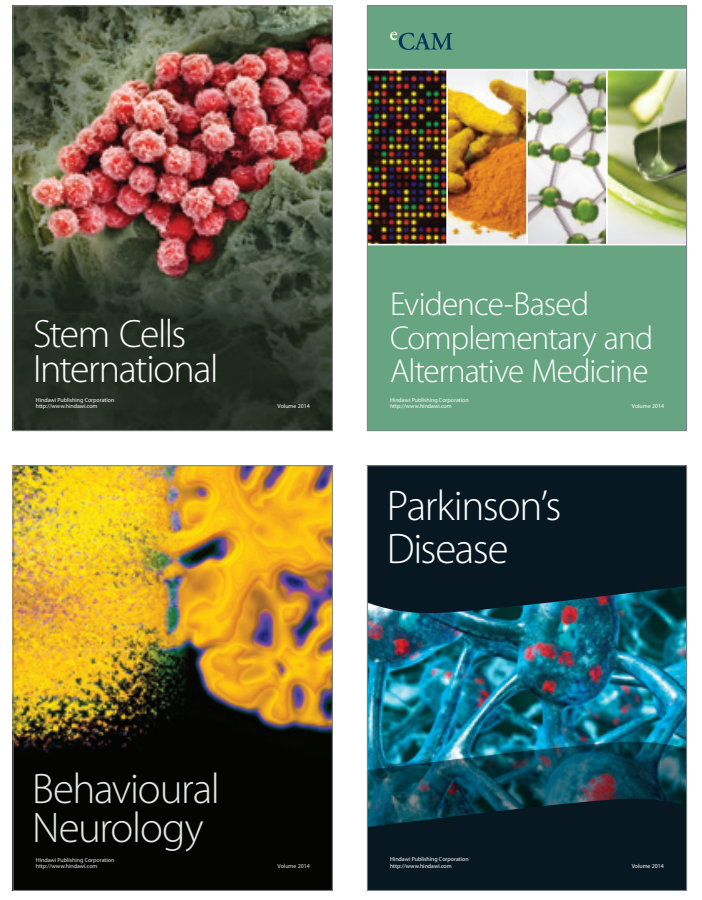
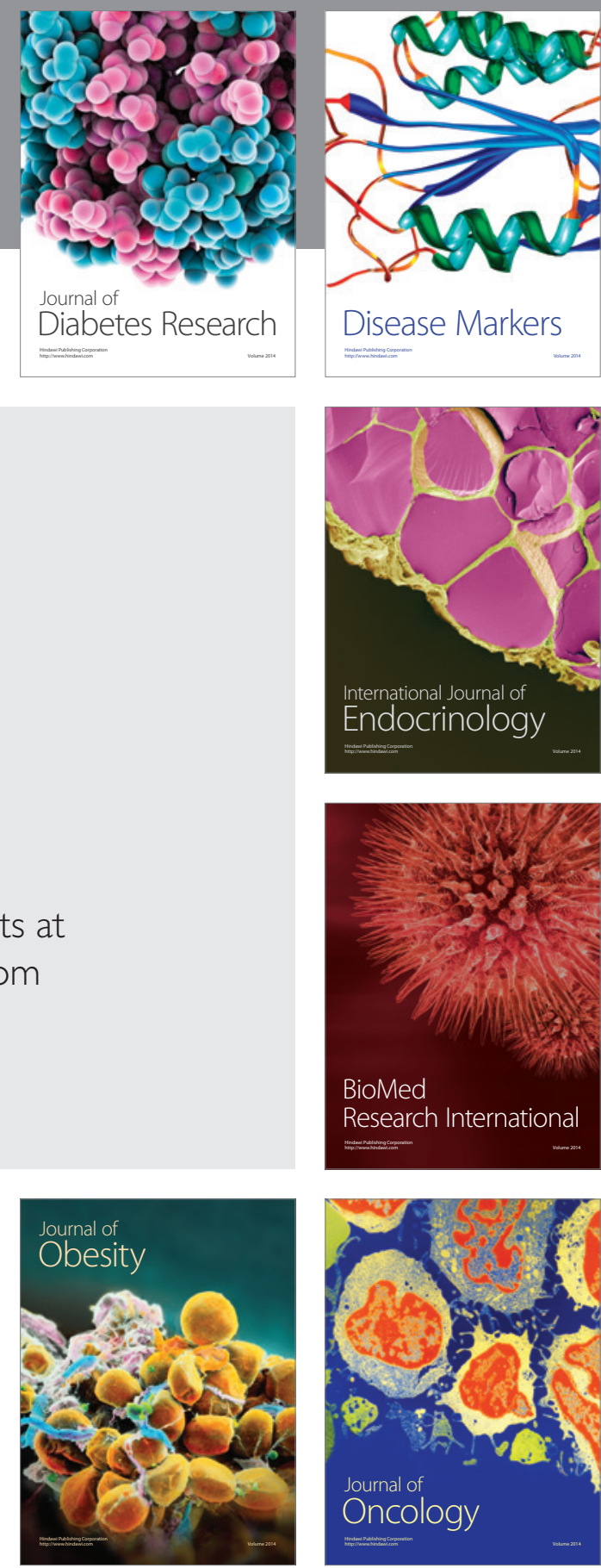

Disease Markers
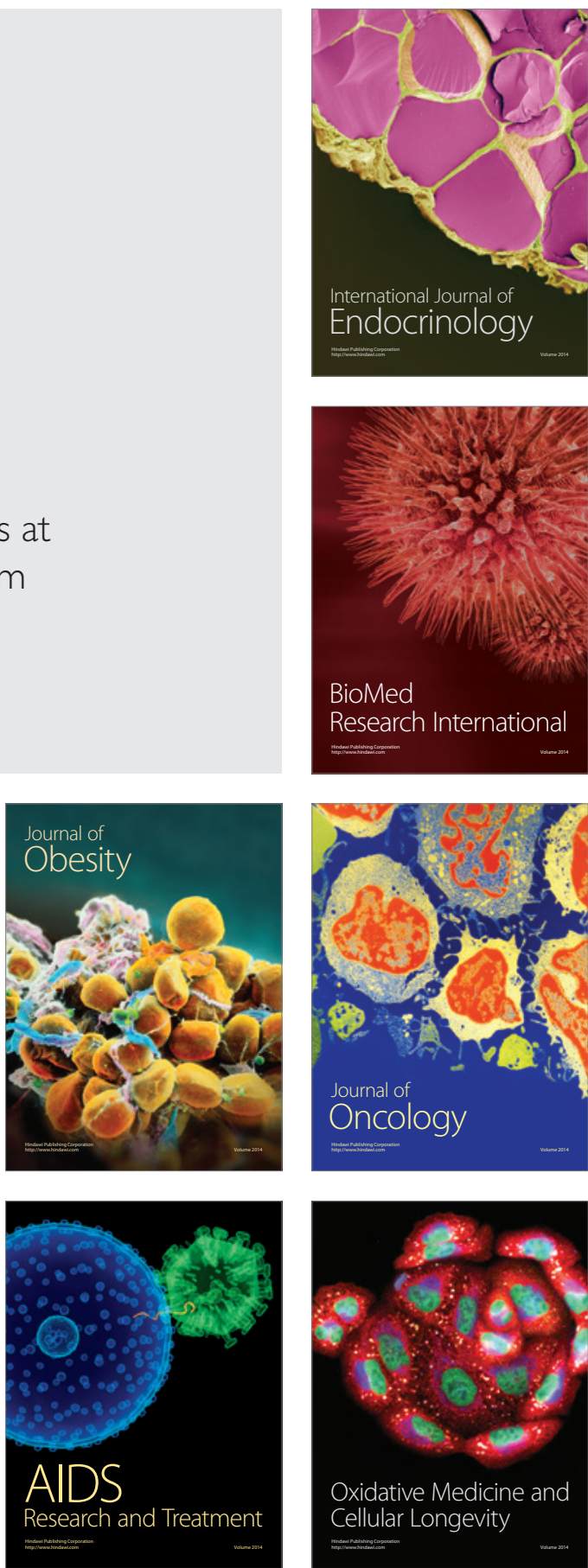